\title{
WIDEBAND VIP POWER DIVIDER WITH DIFFERENTIAL OUTPUT
}

\author{
V. Sokol, K. Hoffmann, Z. Skvor \\ Czech Technical University in Prague, Department of Electromagnetic Field \\ Technicka 2, 16627 Prague 6, Czech Republic \\ Phone: (+420) 22435 2276, Fax: (+420) 233339958 \\ E-mail: sokolvâfel.cvut.cz, Hoffmarn@fel.cvut.cz, skvor@fel.cvut.cz
}

Abstract - A novel wideband VIP power divider with out of phase outputs was designed and experimentally verified. The phase difference $180^{\circ} \pm 5^{\circ}$ and the amplitude difference $\pm 0.8 \mathrm{~dB}$ of output signals were achieved in $4-26 \mathrm{GHz}$ frequency band. Common ground of all coaxial ports is advantageous for application of the component in some differential measurements.

\section{INTRODUCTION}

Differential circuits topologies are becoming common in a wide range of high frequency applications. Theoretical background for measurement of these circuits based on mixedmode scattering parameters was given in [1]. There are thiree current alternatives for the measurement. Mixed-mode network analyzers, standard two-port network analyzers and baluns with a standard twoport network analyzer can be used. There is a restriction of using baluns with respect to their usual narrow bandwidth. The purpose of this paper is to present a novel ultra wide-band balun (power divider) with differential output signals on singleended lines.

There are several possibilities how to obtain 180-degrees phase offset of two identical signals. Transformers are the best solution at low frequencies, while distributed circuit elements are used above about $2 \mathrm{GHz}$. Wilkinson power divider with $\lambda / 2$ line added in one output branch is a simple solution. Standard rat race directional coupler eventually improved with a phase inverter may be also used in different types of lines, see [2], [3]. Dimensions related to wavelength result in limited frequency band that is a common disadvantage of these circuits.

Frequency independent 180-degree phase offset may be also achieved crossing the active and the ground conductor in a single ended line, [4]. However both grounds must be separated by a high impedance element, which is usually realized as a quarter-wavelength short-ended stub. It limits the frequency band as well. Standard baluns between single-ended and balanced lines also need quarterwavelength stubs to prevent currents to flow through undesired parts of ground conductors, [5]. It results again in a narrow frequency band.

\section{THEORY}

The new power divider with differential outputs is based on an inhomogeneous lossy coupled line formed by a parallel plate line placed into a rectangular metal box; see Fig. 1.

Two modes (differential and common) can propagate along the structure stimulated into port 1 . The structure is designed to facilitate strong space

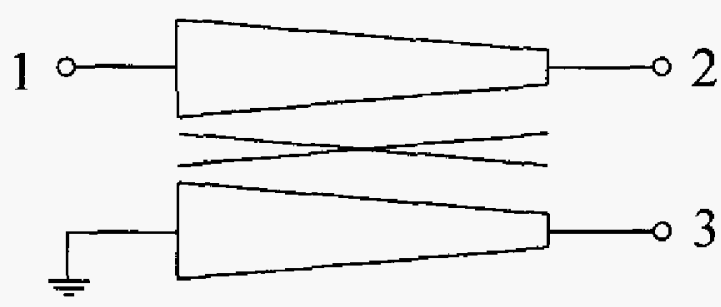

Fig. 1. Equivalent circuit of the power divider. 


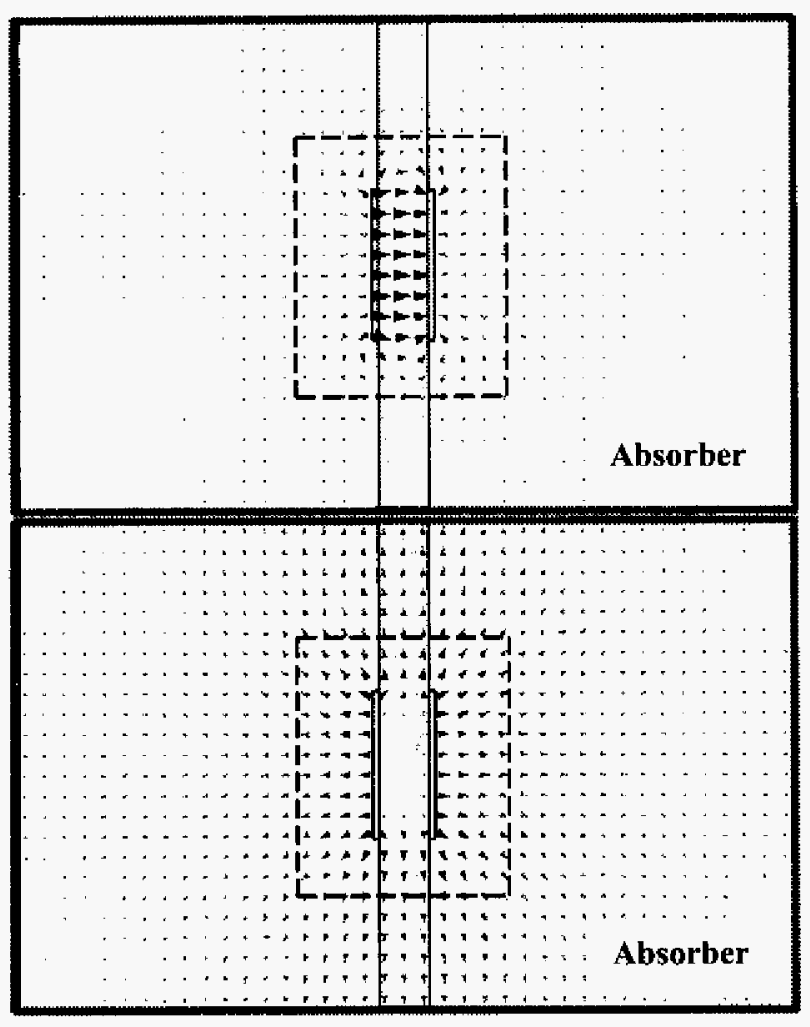

Fig. 2. Differential (top) and common (bottom) modes in the structure.

diversity of both modes. This space diversity enables for efficient suppression of the common mode. The differential mode is concentrated between the conductors of the parallel plate line with very low part of energy into the absorber region, see Fig. 2. On the contrary the common mode is dominantly outside of the line going significantly thru the absorber. Moreover the input differential mode impedance of the coupled line is designed to match the input coaxial/microstrip line. On the contrary the common mode impedance is designed as high as possible.

Under these conditions majority of energy from the input signal is transformed into the differential mode. It makes possible to attenuate the common mode by an absorber while the differential mode remains nearly untouched. A VIP T-junction of the parallel plate line and a standard microstrip line provide an equal splitting of the differential signal, see Fig. 3 .

Equal impedance of all ports can be achieved using inhomogeneous parallel plate line, making corresponding gradual impedance change possible.

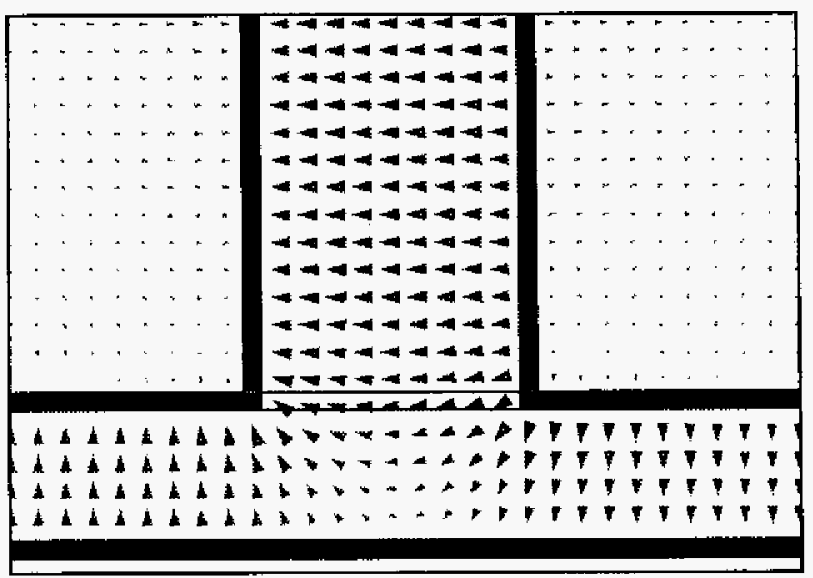

Fig. 3. E-field distribution in the cross-section of the VIP T-junction.

The whole structure is non-resonant and therefore it is able in principle to work in very wide frequency band starting from some low frequency determined by the properties of the absorber and ratio between the mechanical length and the wavelength of the parallel plate line.

\section{DESIGN AND REALIZATION}

EM-simulator CST Microwave Studio ${ }^{6}$ and Microwave Office ${ }^{(1)}$ were used for the development of the structure. It was realized on CuClad 233 substrate with thickness $0.254 \mathrm{~mm}$ and placed into a metal box with inner dimensions $34 \times 21 \times 74 \mathrm{~mm}$. SMA connectors were used at all ports, see Fig. 4. ARC Technologies absorber ARC-LS-10211 suppressed the common mode and the waveguide modes of the box. A simple constant conductivity model of absorber was used for simulation. Agilent E $8364 \mathrm{~A}$ vector network analyzer was used for the measurement in frequency band $2 \div 26 \mathrm{GHz}$.

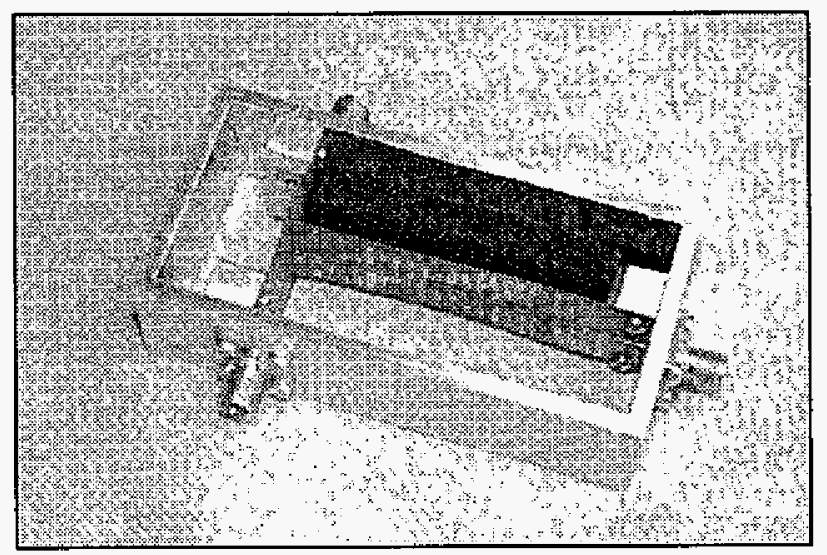

Fig. 4. Realized power divider. Absorber partially removed. 


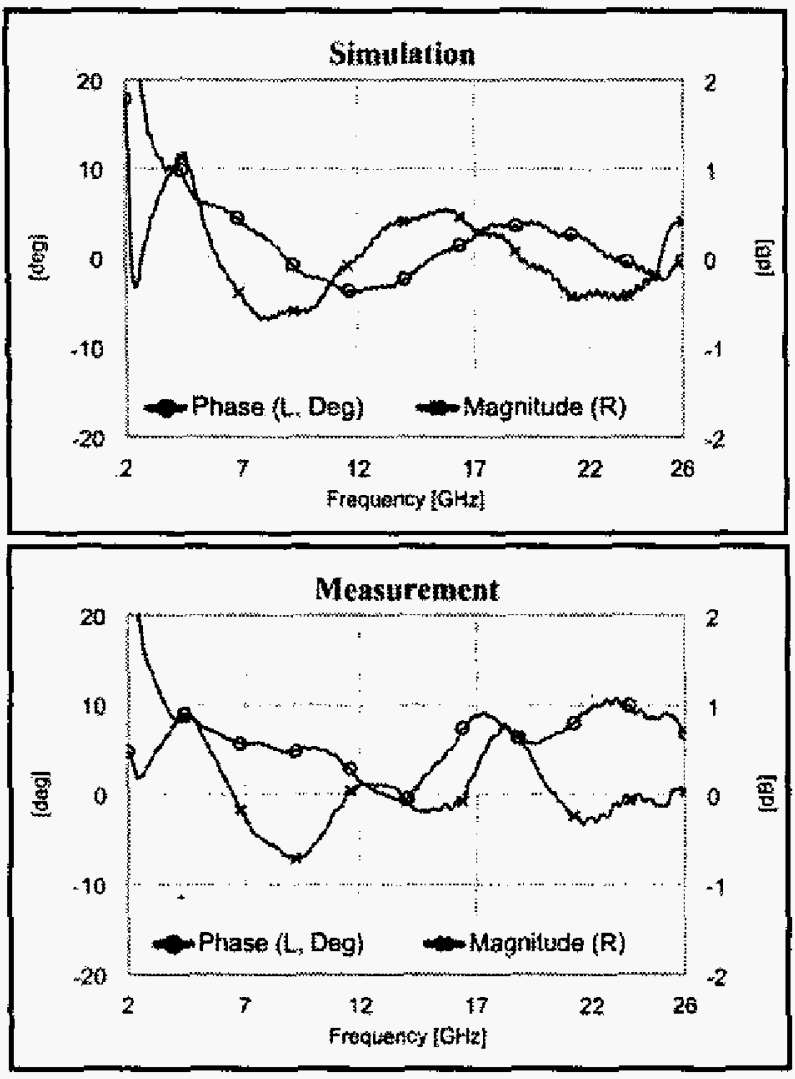

Fig. 5. Simulated and measured output signals. Magnitude difference and phase difference from $180^{\circ}$.

Measured results agree well with the modeled ones, see Fig. 5. The magnitude difference of the output signals below $0.8 \mathrm{~dB}$ and the phase difference from $180^{\circ}$ in the interval of 10 degrees were measured in the frequency band $4-26 \mathrm{GHz}$. Due to mechanical imperfections the measured phase offset about 5 degrees can be seen between outputs. The input reflection coefficient is below $16 \mathrm{~dB}$ up to $22 \mathrm{GHz}$ and $-10 \mathrm{~dB}$ at upper frequency band that is caused by transition SMA connectormicrostrip line. The insertion loss is sloped from 4 $\mathrm{dB} @ 4 \mathrm{GHz}$ to $6 \mathrm{~dB} @ 26 \mathrm{GHz}$. It can be supposed that the structure will work acceptably above 26 $\mathrm{GHz}$.

\section{CONCLUSION}

A new component, power divider in singleended coaxial/microstrip structure with differential output signals, was designed, realized and measured. The measurements of the first realization sample confirmed initial presumptions of its very good properties in wideband frequency range. With respect to its non-resonant resistive nature the frequency band is not limited towards higher frequencies in principle. Common ground on all ports is advantageous for some differential measurements.

The first sample of the power divider was realized using components and materials on the shelf. Wider frequency band is supposed to be achieved with connectors for higher frequencies and the absorber working on lower frequencies.

\section{ACKNOWLEDGEMENT}

This work has been conducted at the Department of Electromagnetic Field of Czech Technical University in Prague and supported by research program "Investigation of new methods for measurement of physical quantities, their application in instrumentation" No.: J04/98:210000015 of the Czech Ministry of Education and grant 102/01/0573 "New methods of broadband vector measurement" of the Grant Agency of Czech Republic.

\section{REFERENCES}

[1] D. E. Bockleman and W. R. Eisenstadt, "Combined Differential and Common-Mode Scattering Parameters: Theory and Simulation," IEEE Trans. Microwave Theory Tech., vol. 43, No. 7, July 1995, pp 1530-1539

[2] C. Ho, L. Fan and K Chang, "Ultra Wide Band Slotline Hybrid Ring Couplers," in IEEE MTTS Int. Microwave Symp. Dig. 1992, pp 1175 1177

[3] T. Wang and $\mathrm{K}$. Wu, "Size-Reduction and Band-Broadening Design Technique of Uniplanar Hybrid Ring Coupler Using Phase Inverter for M(H)MIC's," IEEE Trans. Microwave Theory Tech., vol. 47, No. 2, February 1999, pp. 198-206

[4] C. W. Kao and C. H. Chen, "Novel Uniplanar $180^{\circ}$ Hybrid-Ring Couplers with Spiral-Type Phase Inverters," IEEE Trans. Microwave and Guided Letters, vol. 10, No. 10, October 2000, pp. $412-414$

[5] B. R. Hallford, "A Designer's Guide to Planar Mixer Baluns," Microwaves, December 1979, pp 52-57 